\title{
EVALUASI PROSES PROGRAM PENDIDIKAN KEAKSARAAN DASAR PERSPEKTIF DISCREPANCY EVALUATION MODEL
}

\author{
Marliza Oktapiani \\ Universitas Islam As-Syafi' iyah Jakarta Indonesia \\ marlizaoktapiani.fai@uia.ac.id
}

\begin{abstract}
ABSTRAK
Tujuan dari penelitian ini adalah untuk mengetahui bagaimana evaluasi proses program pendidikan keaksaraan perspektif discrepancy evaluation model. Metode yang digunakan dalam penelitian ini adalah metode kualitatif. Hasil dari penelitian ini menunjukkan bahwa terdapat kesenjangan pada aspek proses program memiliki tiga kesenjangan meliputi penyusunan perangkat pembelajaran (silabus dan RPP), Peningkatan budaya baca, Penilaian proses pembelajaran dan penilaian hasil akhir. Capaian hasil dan dampak program pendidikan keaksaraan dasar belum maksimal dalam memenuhi standar program pendidikan keaksaraan dasar. Simpulan, program ini dianalisis kesenjangannya serta memberikan pemecahan masalah pada setiap aspek berdasarkan tahapan discrepancy evaluation model.
\end{abstract}

Kata Kunci: Discrepancy Evaluation Model, Evaluasi Proses, Keaksaraan Dasar

\section{ABSTRACT}

The purpose of this study is to find out how to evaluate the process of literacy education programs from the perspective of the discrepancy evaluation model. The method used in this research is qualitative method. The results of this study indicate that there are gaps in the aspects of the program process which have three gaps including the preparation of learning tools (syllabus and lesson plans), improvement of reading culture, assessment of learning processes and assessment of final results. The achievements and impacts of the basic literacy education program have not been maximal in meeting basic literacy education program standards. In conclusion, the program analyzed its gaps and provided problem solving in every aspect based on the stage of the discrepancy evaluation model.

Keywords: Process Evaluation, Basic Literacy, Discrepancy Evaluation Model

\section{PENDAHULUAN}

Pelaksanaan program pendidikan keeaksaraan dasar dalam rangka penuntasan tuna aksara di Indonesia, dilakukan atas kerjasama dengan lembaga atau organisasai masyarakat dan satuan pendidikan nonformal dibawah koordinasi Direktorat Pembinaan Pendidikan Keaksaraan dan Kesetaraan atau Dinas Pendidikan provinsi dan Dinas Pendidikan Kabupaten /Kota. Berdasarkan dukungan anggaran yang diberikan Direktorat melalui dana APBN dan APBD memberikan hitungan 
pencapaian kepada warga belajar untuk mengenyam pendidikan kedua (Kementerian Pendidikan dan Kebudayaan, 2015).

Menuju Indonesia yang maju dan bebas buta aksara, maka dengan adanya program pendidikan keaksaraan diharapkan bukan hanya sekedar gerakan nasional, namun kepedulian yang di ikutsertakan oleh gerakan masyarakat sehingga dapat mengurangi angka buta aksara di Indonesia serta meminimalisasikan adanya kesenjangan di tiap daerah. Oleh karena itu, pemerintah Indonesia bersama pemerintah daerah serta kepeduliaan dari masyarakat yang mewujudkan adanya penurunan angka tuna aksara secara bertahap dan berkelanjutan. (Kementerian Pendidikan dan Kebudayaan, 2014).

Tantangan besar dalam pengentasan dan penuntasan tuna aksara saat ini, yaitu: 1) Karakteristik penduduk tuna aksara yang sekitar 3,86\% (2013) sedangkan 3,70\% (2014) adalah mereka dari kelompok paling miskin, terpencil dan terpencar, serta sebagian dari mereka berada pada komunitas dengan budaya tertentu; 2) Masih besarnya jumlah aksarawan baru yang mengalami relapsing (menjadi tuna aksara kembali), karena kurangnya motivasi untuk memelihara melek aksara yang telah diperoleh; 3) Masih besarnya potensi bertambahnya penduduk tuna aksara, yakni dari jumlah siswa SD kelas awal (1-3) yang drop-out, yang berpotensi menjadi tuna aksara. Begitu pula dengan hasil yang ditunjukkan oleh Badan Pusat Statistik bahwa yang terpadat buta aksara tergolong tinggi menurut Data Pusat Badan Statistik ialah Jawa Timur (Kab.Jember 167.118 dan Kab Sumenep 127.408), selanjutnya Jawa Tengah (Kab.Brebes 98.120 dan Kab. Sragen 49.284), Jawa Barat Kab Indramayu 102.118 dan Kab Bogor 98.845) dan Papua (Kab Deiyai 103.675 dan Kab Puncak Jaya 64.515). Dengan berbagai pendekatan kami berusaha tetap memperbaiki program ini dari tahun ketahun. Sehingga tetap melayani yang belum tuntas terlayani (Direktorat Pembinaan Pendidikan Keaksaraan dan Kesetaraan, 2016).

Belajar adalah suatu keharusan, seumur hidup dan kehidupan yang meluas, mereka berfikir bahwa pembelajaran menjadi aktivitas manusia yang sangat penting. Belajar tidak hanya intrinsik tapi juga prasyarat untuk mendapatkan pekerjaan yang baik agar dapat berintegrasi secara sosial serta kesejahteraan dan kebahagiaan individu (Iosifescu, 2014). Pengamanan pendidikan dan pembelajaran untuk masa depan yang berkelanjutan merupakan masalah yang pelik dalam agenda baru ini untuk tahun 2016-2030. Diskusi seputar pencapaian dan kekurangannya kemajuan dalam tujuan pendidikan untuk semua memberikan dorongan baru untuk meningkatkan pembelajaran dan literasi baik di negara maju maupun berkembang (Hanemann, McKay, 2015). Namun pernyataan yang diberikan oleh Gee dan Heath yang dikutip oleh Dewayani, yang menjelaskan bahwa literasi saat ini tak lagi bermakna sebagai pemberantasan buta aksara, namun sebuah praktik sosial yang melibatkan kegiatan berbicara, menulis, membaca, menyimak dalam proses memproduksi ide dan mengkontruksi makna yang terjadi dalam konteks budaya yang spesifik (Dewayani, 2017).

Merujuk data Badan Pusat Statistik bahwa Kabupaten Bogor merupakan Kabupaten dengan tingkat buta aksara tertinggi setelah Kabupaten Indramayu yang berada di provinsi Jawa Barat, serta kabupaten yang mendapatkan distribusi kuota sasaran dan anggaran dengan alokasi 2.500 jiwa dan anggaran mencapai Rp. 
1.125.000.000, maka dari temuan tersebut penulis merasa penting untuk melakukan penelitian di Kabupaten Bogor, mengingat masih tingginya buta aksara dari setiap kecamatan yang berada di kabupaten Bogor tersebut. Selanjutnya, tantangan tersulit terletak pada kesadaran dan komitmen tentang pentingnya keaksaraan. Mungkin sulit untuk mengubah mindset tersebut, mewujudkan lingkungan pembelajar sepanjang hayat dan lingkungan kondusif bagi pendidikan anak-anak, memerlukan masyarakat yang beraksara. Keaksaraan bukan hanya sekedar pemenuhan hak, tetapi kewajiban untuk membukakan pintu menuju pembangunan nasional berbasis pengetahuan. Banyak kemajuan telah di raih untuk mencapai target 2015 dalam bidang keaksaraan, namun tantangan berat di masa yang akan datang tetap ada.

\section{METODE PENELITIAN}

Penelitian dilakukan dengan menggunakan metode kualitatif dan pendekatan discrepancy evaluation model. Data primer dalam penelitian diperoleh langsung oleh dari kegiatan program pendidikan keaksaraan dasar yang di amati melalui kegiatan warga belajar dalam melaksanakan prose kegiatan pembeljaran pada program pendidikan keaksaraan dasar. Selanjutnya data diperoleh dari sumber data sekunder yang tidak langsung memberikan data kepada pengumpul data. Data sekunder yang dimaksudkan adalah data arsip, serta dokumen-dokumen tentang beberapa hal yang terkait dengan kegiatan pendidikan di PKBM yang berada di Kabupaten Bogor.

Penelitian ini di laksanakan di Pusat Kegiatan Belajar Masyarakat di lima PKBM yang mendapatkan APBD tahun 2017 di Kabupaten Bogor. Teknik pengumpulan data dengan wawancara, observasi dan dokumentasi. Sebagai upaya untuk menjawab tujuan penelitian maka dalam penelitan ini digunakan metode penelitian yang bersifat evaluatif yang mendalam terkait dengan proses Produk. Model DEM yang dipilih dengan mengidentifikasi satu tahapan spesifik untuk program, yaitu: Tahap Proses Program - dimana tujuan dari evaluasi adalah untuk menilai hubungan antara variabel dengan proses yang digunakan untuk memberikan dampak serta perubahan. Tahap proses program bertanya, "Apakah sumber sumber dan teknik yang digunakan selaras dengan tujuan program?.

\section{HASIL PENELITIAN}

Tabel 1 Perbandingan Kondisi Obyektif Proses dengan Standar

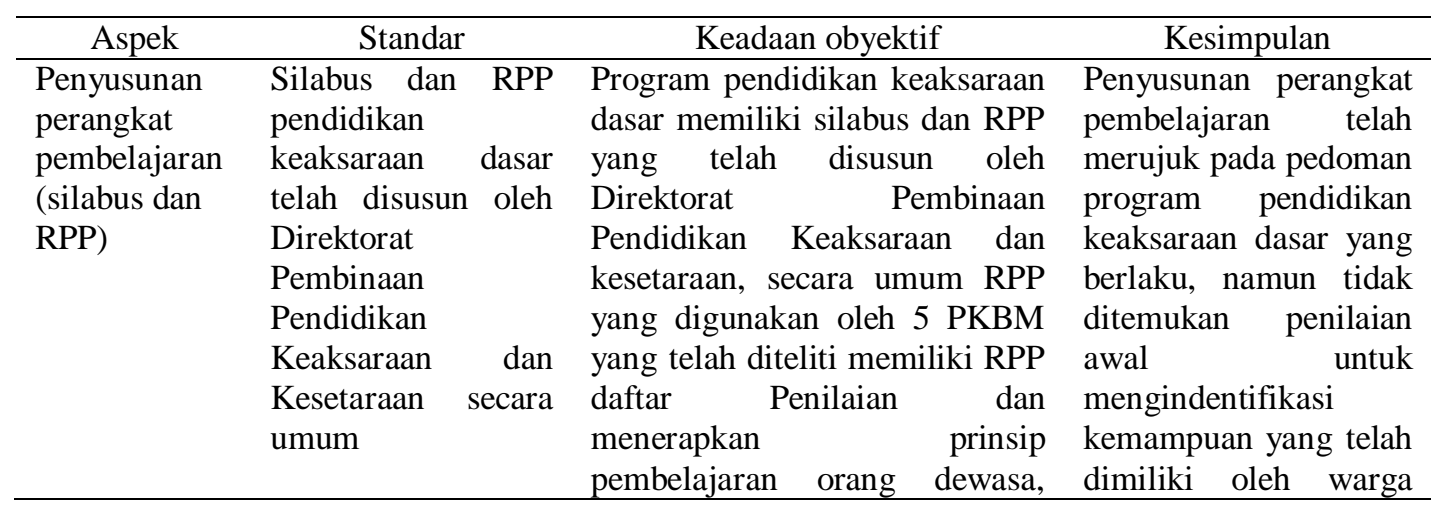




\begin{tabular}{|c|c|c|c|}
\hline Aspek & Standar & Keadaan obyektif & Kesimpulan \\
\hline & & $\begin{array}{l}\text { namun terdapat kelemahan, } \\
\text { belum ditemukan hasil analisis } \\
\text { penilaian awal pada kemampuan } \\
\text { warga belajar sehingga } \\
\text { pembelajaran berdasarkan rpp } \\
\text { dan kesepakatan pembelajaran } \\
\text { yang berlaku. }\end{array}$ & belajar. \\
\hline $\begin{array}{l}\text { Prinsip } \\
\text { pembelajaran } \\
\text { keaksaraan } \\
\text { dasar dan } \\
\text { penerapan } \\
\text { pembelajaran } \\
\text { orang dewasa }\end{array}$ & $\begin{array}{l}\text { Prinsip } \\
\text { pembelajaran dan } \\
\text { penerapan } \\
\text { pembelajaran } \\
\text { program pendidikan } \\
\text { keaksaraan dasar }\end{array}$ & $\begin{array}{l}\text { Pelaksanaan } \\
\text { mencerminkan program } \\
\text { penbelajaran keaksaraan dasar } \\
\text { dan menerapkan pembelajaran } \\
\text { orang dewasa, Kondisi prinsip } \\
\text { pembelajaran pendidikan } \\
\text { keaksaraan dasar di kabupaten } \\
\text { Bogor menerapkan berbagai } \\
\text { kriteria, pada pengamatan } \\
\text { ditemukan kartisipatif, } \\
\text { kontekstual, konteks lokal, } \\
\text { kooperatif dan kolaboratif, } \\
\text { tematik, desain lokal, } \\
\text { fungsionalisasi hasil belajar dan } \\
\text { fleksibel, namun kondisi prinsip } \\
\text { fleksibel tidak teramati pada } 5 \\
\text { PKBM mengubah rencana } \\
\text { pembelajaran yang disesuaikan } \\
\text { dengan dinamika, karena } \\
\text { kemungkinan terdapat peserta } \\
\text { didik yang memiliki } \\
\text { kemampuan tinggi, sedang dan } \\
\text { rendah maupun heterogenan } \\
\text { lainnya tidak didentifikasi sejak } \\
\text { awal. }\end{array}$ & $\begin{array}{lr}\text { Prinsip pembelajaran } \\
\text { keaksaraan dasar dan } \\
\text { penerapan } \\
\text { pembelajaran } & \text { orang } \\
\text { dewasa } & \text { secara } \\
\text { prinsipnya } & \text { telah } \\
\text { dilakukan } & \text { secara } \\
\text { bervariasi } & \text { sesuai } \\
\text { karakteristik } & \\
\text { pembelajaran } & \\
\text { diwilayah tersebut. }\end{array}$ \\
\hline $\begin{array}{l}\text { Penggunaan } \\
\text { metode, } \\
\text { media dan } \\
\text { sumber } \\
\text { belajar }\end{array}$ & $\begin{array}{l}\text { Metode, media dan } \\
\text { sumber belajar } \\
\text { pendidikan } \\
\text { keaksaraan dasar }\end{array}$ & $\begin{array}{l}\text { Teknik yang digunakan pada } \\
\text { program pendidikan keaksaraan } \\
\text { dasar di Kabupaten Bogor lebih } \\
\text { menekankan pada membaca } \\
\text { melalui bacaan sederhana yang } \\
\text { menggunakan media belajar } \\
\text { berupa poster abjad dan kartu } \\
\text { tempel. sedangkan sumber } \\
\text { belajar yang dapat digunakan } \\
\text { dalam proses pembelajaran } \\
\text { pendidikan keaksaraan dasar di } \\
\text { Kabupaten Bogor yaitu belajar } \\
\text { pada lingkungan alam sekitar, } \\
\text { benda yang ada disekeliling } \\
\text { orang yang belajar, dan } \\
\text { membaca buku yang telah } \\
\text { diberikan oleh Kementerian } \\
\text { Pendidikan dan Kebudayaan. } \\
\text { Peserta didik atau warga belajar }\end{array}$ & 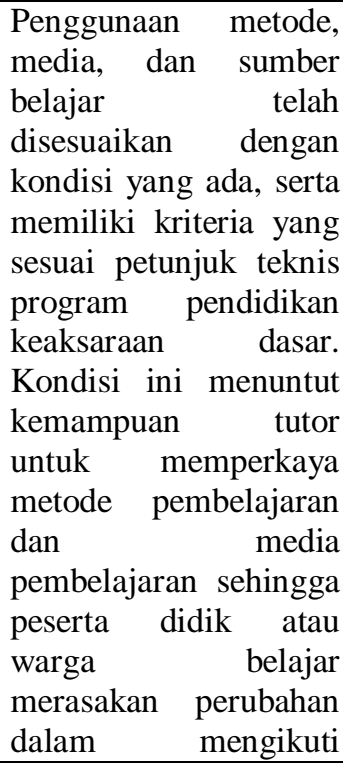 \\
\hline
\end{tabular}




\begin{tabular}{|c|c|c|c|}
\hline Aspek & Standar & Keadaan obyektif & Kesimpulan \\
\hline & & $\begin{array}{l}\text { telah mendapatkan modul, buku, } \\
\text { dan alat tulis yang tidak } \\
\text { dibebankan kepada warga } \\
\text { belajar. }\end{array}$ & $\begin{array}{l}\text { program pendidikan } \\
\text { keaksaraan dasar di } \\
\text { Kabupaten Bogor. }\end{array}$ \\
\hline $\begin{array}{l}\text { Peningkatan } \\
\text { budaya baca }\end{array}$ & $\begin{array}{l}\text { Budaya baca dan } \\
\text { strategi } \\
\text { meningkatkan } \\
\text { minat baca }\end{array}$ & $\begin{array}{l}\text { Pada akhir proses pembelajaran } \\
\text { terdapat warga belajar yang } \\
\text { menyampaikan kepada tutor } \\
\text { apakah ketika pembelajaran ini } \\
\text { berakhir warga belajar boleh } \\
\text { meminta tambahan waktu } \\
\text { belajar untuk meneruskan } \\
\text { tulisan yang belum selesai serta } \\
\text { membaca kembali bacaan yang } \\
\text { belum dianggap lancer. Proses } \\
\text { pembelajaran di PKBM Kartini } \\
\text { telah menggunakan strategi } \\
\text { dengan membaca permulaan } \\
\text { dan membaca bersuara. PKBM } \\
\text { lain menggunakan metode } \\
\text { memberi kesempatan kepada } \\
\text { warga belajar untuk memulai } \\
\text { dengan membaca } 5 \text { menit yang } \\
\text { disajikan dengan caranya } \\
\text { sendiri. Khusus PKBM Al- } \\
\text { Hikmah merupakan salah satu } \\
\text { PKBM yang mengikuti } \\
\text { perlombaaan dan mendapatkan } \\
\text { prestasi dalam lomba } \\
\text { keberaksaraan fungsional } \\
\text { dengan kategori perlombaaan } \\
\text { menulisa biodata dan } \\
\text { membacakan biodata. }\end{array}$ & 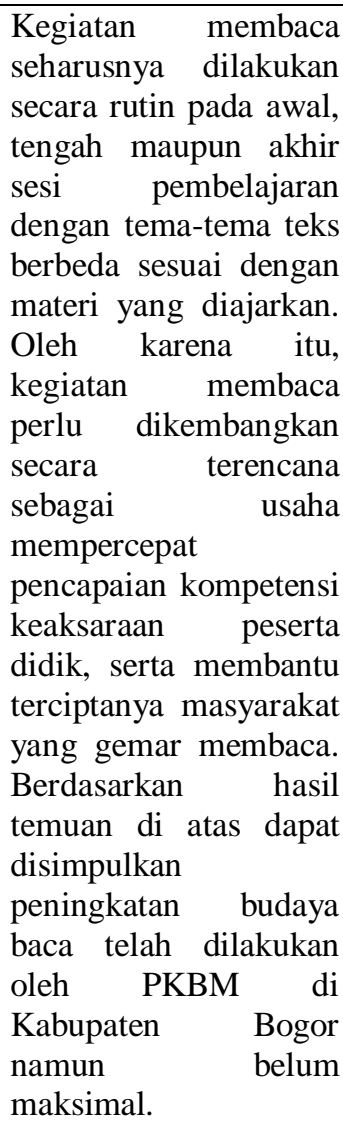 \\
\hline $\begin{array}{l}\text { Penguatan } \\
\text { motivasi } \\
\text { belajar } \\
\text { peserta didik }\end{array}$ & $\begin{array}{l}\text { Motivasi belajar } \\
\text { peserta didik } \\
\text { program pendidikan } \\
\text { keaksaraan dasar }\end{array}$ & $\begin{array}{l}\text { Tutor memberikan motivasi } \\
\text { kepada warga belajar apabila } \\
\text { dapat menjawab pertanyaan } \\
\text { dengan memberikan uang } \\
\text { sebesar dua puluh ribu rupiah. } \\
\text { Setiap pembelajaran tutor tidak } \\
\text { pernah membandingkan peserta } \\
\text { didik. PKBM di bawah binaan } \\
\text { Dinas Pendidikan Kabupaten } \\
\text { Bogor menunjukkan bahwa } \\
\text { setiap tutor melakukan } \\
\text { penguatan motivasi belajar } \\
\text { kepada warga belajarnya } \\
\text { termasuk peneliti memberikan } \\
\text { cendramata bagi warga belajar } \\
\text { sebagai tanda perkenalan dan } \\
\text { memberikan semangat kepada } \\
\text { warga belajar agar terus } \\
\text { melanjutkan program sampai }\end{array}$ & $\begin{array}{l}\text { Penguatan motivasi } \\
\text { belajar telah dilakukan } \\
\text { dan telah berpedoman } \\
\text { kepada panduan } \\
\text { penyelenggaran dan } \\
\text { pembelajaran program } \\
\text { pendidikan keaksaraan } \\
\text { dasar yang ada di } \\
\text { kabupaten Bogor }\end{array}$ \\
\hline
\end{tabular}




\begin{tabular}{|c|c|c|c|}
\hline Aspek & Standar & Keadaan obyektif & Kesimpulan \\
\hline & & $\begin{array}{l}\text { akhir pembelajaran. Informasi } \\
\text { yang di dapatkan pada tahun } \\
\text { sebelumnya salah satu PKBM } \\
\text { yang diteliti yaitu PKBM Prima } \\
\text { Lestari mendapatkan bantuan } \\
\text { kacamata untuk } 20 \text { warga } \\
\text { belajar. Penguatan motivasi } \\
\text { yang dilakukan oleh Dinas } \\
\text { Pendidikan dan Kebudayaan } \\
\text { yang bekerjasama dengan Dinas } \\
\text { Kesehatan setempat } \\
\text { ditindaklanjuti oleh puskesmas } \\
\text { untuk warga belajar yang } \\
\text { memiliki permasalahan pada } \\
\text { indera penglihatannya.Terkait } \\
\text { dengan penguatan motivasi } \\
\text { belajar diketahui pernyataan } \\
\text { tutor selalu memberikan } \\
\text { motivasi kepada kami seperti, } \\
\text { memberikan hadiah, } \\
\text { mengucapkan kata-kata positif, } \\
\text { peduli terhdap peserta didik, } \\
\text { tidak berorientasi dengan nilai.. }\end{array}$ & \\
\hline $\begin{array}{l}\text { Remedial/pen } \\
\text { gayaan } \\
\text { pembelajaran }\end{array}$ & $\begin{array}{l}\text { Peserta didik } \\
\text { mendapatkan tindak } \\
\text { lanjut pembelajaran } \\
\text { yang bertujuan } \\
\text { untuk membantu } \\
\text { mengatasi kesulitan } \\
\text { belajar }\end{array}$ & 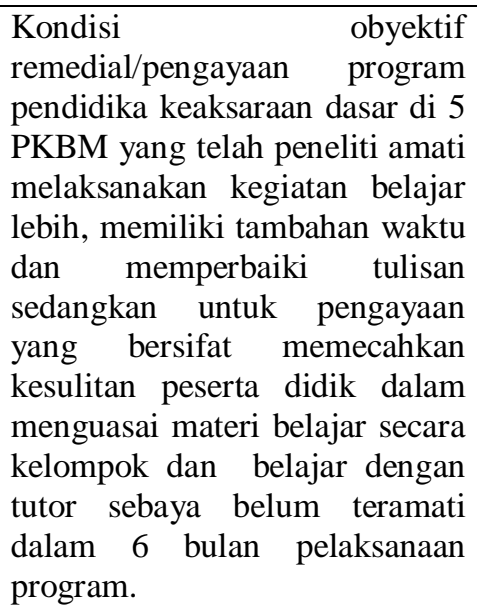 & 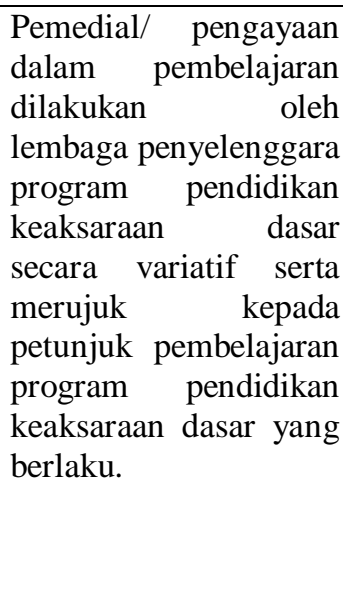 \\
\hline $\begin{array}{l}\text { Penilaian } \\
\text { proses } \\
\text { pembelajaran } \\
\text { dan hasil } \\
\text { akhir belajar }\end{array}$ & $\begin{array}{l}\text { Memperoleh } \\
\text { informasi } \\
\text { berkenaan tingkat } \\
\text { keberhasilan } \\
\text { pembelajaran, } \\
\text { menghimpun data } \\
\text { peserta didik yang } \\
\text { lulus dan berhak } \\
\text { mendapatkan } \\
\text { SUKMA dengan } \\
\text { memperhatikan } \\
\text { minimal nilai yang } \\
\text { diperoleh yaitu } 55\end{array}$ & $\begin{array}{l}\text { TIM pelaksana menyerahkan } \\
\text { laporan pelaksanaan penilaian } \\
\text { akhir kepada Dinas Pendidikan } \\
\text { Kabupaten Bogor yang } \\
\text { ditembuskan pada Kementerian } \\
\text { Pendidikan dan Kebudayaan. } \\
\text { Berdasarkan laporan dokumen } \\
\text { penilaian TIM diketahui PKBM } \\
\text { telah memberikan laporan } 1 \\
\text { bulan setelah proses } \\
\text { pembelajaran berakhir (Program } \\
\text { Berakhir). Laporan program } \\
\text { disertakan dengan laporan }\end{array}$ & 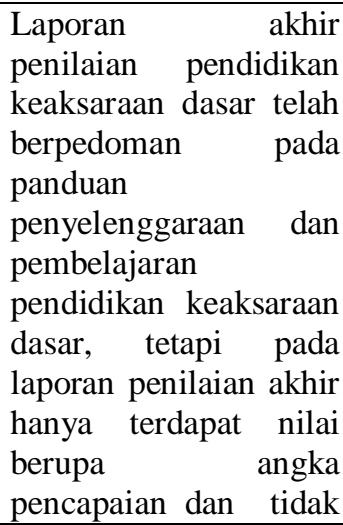 \\
\hline
\end{tabular}




\begin{tabular}{|c|c|c|c|}
\hline Aspek & Standar & Keadaan obyektif & \\
\hline & $\begin{array}{l}\text { dengan } \\
\text { cukup, } \\
\text { baik bersikap } \\
\text { pembelajaran serta } \\
\text { disiplin selama } \\
\text { mengikuti } \\
\text { pembelajaran }(80 \% \\
\text { kehadiran dari } 114 \\
\text { jam pelajaran) }\end{array}$ & $\begin{array}{l}\text { pertanggung } \\
\text { penggunaan APBan } \\
\text { lampiran. Berdasarkan hasil } \\
\text { studi dokumentasi dan hasil } \\
\text { pengamatan dapat disimpulkan } \\
\text { bahwa lima PKBM yang } \\
\text { menjadi objek penelitian telah } \\
\text { mendapatkan bantuan anggaran } \\
\text { program pendidikan keaksaraan } \\
\text { dasar dan telah mengumpulkan } \\
\text { laporan akhir sesuai waktu yang } \\
\text { telah diberikan. Pelaporan akhir } \\
\text { pembelajaran serta pelaporan } \\
\text { akhir program pendidikan } \\
\text { keaksaraan dasar memiliki } \\
\text { tindak lanjut yang dapat di } \\
\text { sosialisasikan kepada warga } \\
\text { belajar. Berdasarkan hasil studi } \\
\text { dokumentasi terdapat panduan } \\
\text { penilaian akhir pendidikan } \\
\text { keaksaraan dasar. Tindak lanjut } \\
\text { yang pertama adalah } \\
\text { memberikan SUKMA kepada } \\
\text { peserta didik yang telah } \\
\text { memiliki ketuntasan belajar, } \\
\text { serta difasilitasi agar termotivasi } \\
\text { menjadi peserta didik program } \\
\text { paket A atau program } \\
\text { pendidikan keaksaraan lanjutan } \\
\text { (Keaksaraan Usaha Mandiri } \\
\text { atau Multi Keaksaraan). Peserta } \\
\text { yang tidak memperoleh } \\
\text { SUKMA difasilitasi dengan } \\
\text { kegiatan remedial dan/atau } \\
\text { mengulang pembelajaran dan } \\
\text { jika terlihat sudah siap, bisa } \\
\text { dilakukan penilaian akhir } \\
\text { kembali. }\end{array}$ & $\begin{array}{l}\text { mendeskripsikan } \\
\text { pencapaian } \\
\text { kompetensi, sehingga } \\
\text { tidak diketahui } \\
\text { kompetensi apa yang } \\
\text { belum terpenuhi. }\end{array}$ \\
\hline $\begin{array}{l}\text { Monitoring, } \\
\text { evaluasi dan } \\
\text { pengawasan }\end{array}$ & $\begin{array}{l}\text { Desain program } \\
\text { mendeskripsikan } \\
\text { tentang monitoring, } \\
\text { evaluasi dan } \\
\text { pengawasan proses } \\
\text { program pendidikan } \\
\text { keaksaraan dasar } \\
\text { dan mendapatkan } \\
\text { informasi mengenai } \\
\text { indikator } \\
\text { keberhasilan } \\
\text { program sesuai } \\
\text { petunjuk teknis } \\
\text { program pendidikan }\end{array}$ & $\begin{array}{lr}\text { Monitoring, evaluasi } & \begin{array}{r}\text { dan } \\
\text { pengawasan dilakukan oleh }\end{array} \\
\text { penyelenggara dan diawasi serta } \\
\text { dievaluasi oleh } \\
\text { penilik/pengawas } \\
\text { penyelenggara menyampaikan } \\
\text { kesesuaian proses program } \\
\text { pendidikan keaksaraan dasar, } \\
\text { penilik/pengawas mengisi buku } \\
\text { tamu dinas dan memberi catatan } \\
\text { mengenai saran dan kritik } \\
\text { mengenai program yang sedang } \\
\text { dilaksanakan }\end{array}$ & $\begin{array}{l}\text { Berdasarkan } \\
\text { pengamatan, } \\
\text { wawancara, dan studi } \\
\text { dokumentasi } \\
\text { disimpulkan } \\
\text { monitoring, evaluasi, } \\
\text { dan pengawasan telah } \\
\text { dilaksanakan sesuai } \\
\text { dengan panduan } \\
\text { penyelenggara program } \\
\text { pendidikan keaksaraan } \\
\text { dasar }\end{array}$ \\
\hline
\end{tabular}




\begin{tabular}{cccc}
\hline Aspek & Standar & Keadaan obyektif & Kesimpulan \\
\hline & keaksaraan dasar. & &
\end{tabular}

Ketercapaian proses 4 Aspek memenuhi standar

Ketidaktercapaian proses3 Aspek belum maksimal memenuhi standar

Kesenjangan pada penelitian ini menunjukkan terdapat kesenjangan pada aspek proses program memiliki 3 kesenjangan meliputi penyusunan perangkat pembelajaran (Silabus dan RPP), Peningkatan budaya baca, Penilaian proses pembelajaran dan penilaian hasil akhir. Adapun peta konsep kesenjangan pada aspek proses terlampir dibawah ini:

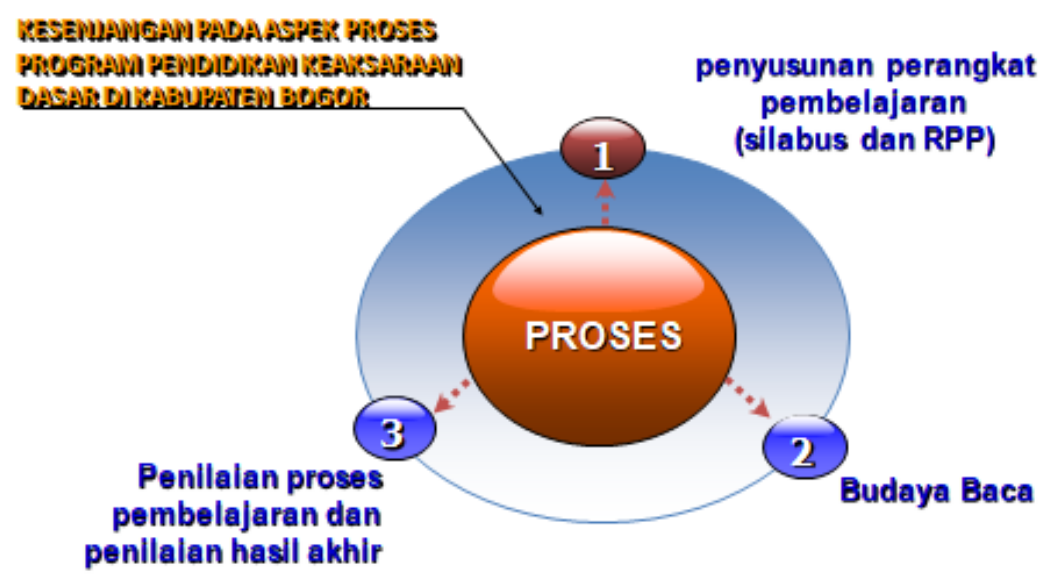

\section{PEMBAHASAN}

\section{Perangkat Pembelajaran (Silabus dan RPP)}

Hasil penilaian mengacu kepada Proses Program Pendidikan Keaksaraan Dasar Selanjutnya disesuai dengan model evaluasi kesenjangan (The Discrepancy Evaluation Model) yang membandingkan kondisi obyektif proses dengan standatr program pendidikan keaksaraan dasar.

Pelaksanaan proses penelitian ini, menemukan beberapa fakta yang ditemukan dalam penelitian, menganalisis, menyatukan berbagai perspektif dari informan dan mengindentifikasi berbagai ketimpangan dengan kriteria atau standar evaluasi yang telah ditentukan. Proses tersebut, dilakukan melalui teknik pengumpulan data yang diperoleh melalui wawancara, observasi dan dokumentasi.

Perencanaan pembelajaran program pendidikan keaksaraan dasar di Kabupaten Bogor harus merujuk pada silabus pedoman pelaksanaan dan pembelajaran pendidikan keaksaraan dasar. Berdasarkan hasil studi dokumentasi program pendidikan kekasaraan dasar bahwa program pendidikan keaksaraan dasar telah berpanduan pada penyelenggaraan dan pembelajaran pendidikan keaksaraan dasar.

While the recognition of the importance of quality criteria by a large number of countries is obviously a necessary first step in raising the quality of adult education, a major issue remains to be tackled: How do countries link the different phases of the 
adult learning and aducation process (input, process, output and outcome) to curriculum specifications (syllabi,teaching methods, qualification standars based on learning outcomes) (Sloane and Dilger, 2005).

Studi dokumentasi lainnya telah menunjukkan bahwa program pendidikan keaksaraan dasar harus mengkondisikan peserta didik dengan penerapan pembelajaran orang dewasa. Setiap akan dimulai atau perggantian tema belajar pendidik berkewajiban menjelaksan kepada peserta didik tentang materi serta tujuan dan hasil apa yang diharapkan. Pengajar telah menyesuaikan materi pelajaran melalui kemampuan peserta didik, memberikan penguatan dan umpan balik, serta memulai dan mengakhiri pembelajaran dengan mengacu pada RPP. Hasil observasi pada perencaanan pembelajaran dan pelaksanaan pembelajaran (RPP) telah dibuat oleh setiap lembaga tetapi RPP yang ada belum mengacu pada standar yang telah ditentukan, kurang penjabaran mengenai standar kompetensi lulusan, standar isi, standar proses, dan terdapat beberapa kelemahan dalam standar penilaian.

\section{Peningkatan Budaya Baca}

Berdasarkan hasil peneliti diketahui bahwa. Proses pembelajaran di PKBM telah menggunakan strategi dengan membaca permulaan dan membaca bersuara. Paulo Freire menyatakan:

Every reading of the word is preceded by a reading of the world. Starting from the reading of the world that the reader brings to literacy programs (a social-and class-determined reading), the reading of the word sends the reader back to the previous reading of the world, which is, in fact, a rereading (Paulo Freire, 1993).

Selain itu PKBM itu telah digunakan metode memberi kesempatan kepada warga belajar untuk memulai dengan membaca 5 menit. Hal ini menunjukkan bahwa peningkatan budaya baca telah dilakukan dan berpedoman pada panduan penyelenggaraan dan pembelajaran program pendidikan keaksaraan dasar.

\section{Penilaian Proses Pembelajaran dan Hasil Akhir}

Berdasarkan hasil studi dokumentasi diketahui bahwa PKBM telah melakukan penilaian proses pembelajaran program pendidikan keaksaraan dasar namun masih terdapat kekurangan penilaian kompetensi yang ditargetkan yaitu kompetensi sikap, pengetahuan, dan keterampilan. Hasil ini menunjukkan perlu adanya tindak lanjut untuk memberikan informasi dan pengetahuan kepada lembaga penyelenggara serta tutor untuk merencanakan secara sistematis pada target penilaian setelah proses pembelajaran keaksaraan dasar berakhir. Jika peserta program tidak memiliki pencapaian yang sesuai dengan standar ketuntasan, maka PKBM di kabupaten Bogor melakukan remedial melalui kegiatan pengayaan serta menambah pengetahuan dan keterampilan, baik secara individu maupun kelompok yang dapat dilakukan dengan memberikan tugas-tugas (membaca, menulis, dan berhitung).

Berdasarkan hasil hasil studi dokumentasi menunjukkan adanya panduan penyelenggaraan dan pembelajaran pendidikan keaksaraan dasar yang memuat penilaian akhir pada pendidikan keaksaraan dasar. Penilaian akhir yang dilakukan oleh lembaga meliputi pengetahuan dan keterampilan dalam membaca, mengenal huruf, membaca suku kata dan memahami teks. Sedangkan penilaian menulis dapat 
meliputi teknik menulis, menulis kata, dan kalimat minimal tiga kalimat dan berhitung meliputi mengenal dan menulis bilangan, melakukan operasi hitung, dan menggunakan uang satuan.

Hasil penilaian pendidikan keaksaraan dasar oleh tutor dilaporkan dalam bentuk nilai dan deskripsi pencapaian kompetensi. Berdasarkan hasil laporan lima PKBM yang telah menyelenggarakan program pendidikan keaksaraan dasar tahun 2017 bahwa penilaian laporan akhir warga yang berhak lulus dan memperoleh SUKMA minimal memiliki nilai 55 dengan kriteri cukup, bersikap baik selama pembelajaran serta disiplin selama mengikuti pembelajaran (80\% kehadiran dari 114 jam pelajaran).

Hasil ini menunjukkan bahwa penilaian formatif telah terbukti memberikan kontribusi yang signifikan terhadap hasil belajar relatif terhadap strategi pengajaran dan pembelajaran (Black and Wiliam, 1998, 2003). Black and Wiliam (1998, 2003) say formative assessment has been shown to make a significant contribution to learning gains relative to other teaching and learning strategies.

Dalam Permendikbud Nomor 86 Tahun 2014 dinyatakan bahwa pedoman penyelenggaraan Pendidikan keaksaraan dasar, mengenai pembelajaran pendidikan keaksaraan dasar mengacu kepada standar Kompetensi lulusan, Kompetensi inti, dan Kompetensi dasar pendidikan keaksaraan dasar. Selanjutnya dalam pelaksanaan pendidikan keaksaraan dasar memiliki pembelajaran minimal 114 jam @60 menit yang berdasarkan pada 3 dimensi yaitu sikap, pengetahuan, dan keterampilan. Standar Kompetensi Dimensi sikap adalah setiap lulusan diharapkan memiliki perilaku dan etika yang mencerminkan sikap orang beriman dan bertanggung jawab dalam berinteraksi dengan lingkungan keluarga, masyarakat, dan alam dalam kehidupan sehari-hari. Standar Kompetensi Dimensi Pengetahuan yaitu menguasai pengetahuan faktual tentang cara berkomunikasi melalui bahasa Indonesia dan berhitung untuk melakukan aktivitas seharihari dalam kehidupan keluarga dan bermasyarakat. Sedangkan dimensi keterampilan yaitu mampu menggunakan bahasa Indonesia dan keterampilan berhitung untuk melakukan aktivitas sehari-hari dalam kehidupan keluarga dan bermasyarakat.

Secara khusus pendidikan keaksaraan dasar yang ada di kabupaten Bogor memiliki kompetensi lokal yaitu dengan adanya pendidikan keaksaraan dasar, lulusan diharapkan (1) menjalankan ibadah sesuai dengan agama dan kepercayaan masingmasing sehingga dapat berprilaku dan memiliki etika sebagai warga masyarakat yang baik; (2) menguasai pengetahuan faktual tentang cara mendengar, membaca, menulis dan berbicara dalam bahasa Indonesia, serta berhitung untuk menyelesaikan masalah seharihari; (3) Mampu membaca, menulis, berbicara dan berhitung untuk mendukung aktivitas dilingkungan keluarga dan masayarakatt dalam kehidupan sehari-hari.

Berdasarkan hasil observasi diketahui bahwa peserta telah memiliki sikap, pengetahuan, dan keterampilannya. Berdasarkan hasil wawancara dengan tutor dan tenaga administrator diketahui bahwa lulusan program pendidikan keaksaraan dasar telah mengacu kepada petunjuk teknis program pendidikan keaksaraan dasar yang mengedapankan kepada sikap, pengetahuan dan keterampilan serta mengacu kepada permendikbud yang ada. Tetapi dalam prakteknya masih kurang terpenuhi beberapa capaian yang ditetapkan. 


\section{SIMPULAN}

Proses program pendidikan keaksaraan dasar merupakan capaian sementara dari program pendidikan keaksaraan dasar yang menitikberatkan pada pencapaian pembelajaran dan mendukung ketercapaian dari setiap indikator, proses ini menjadikan gambaran keberhasilan sementara program untuk ditindaklanjuti agar mendorong penurunan buta aksara yang ada di daerah titik terpadat buta aksara, proses akan menjamin mutu pembelajaran tercapai sehingga memerlukan desain yang matang dalam pemenuhan program dimasa yang akan datang sehingga kesenjangan yang ditemukan dapat memberi masukan guna perubahan pendektan proses pembelajaran program pendidikan keaksaraan pada tahun mendatang.

\section{DAFTAR PUSTAKA}

Black, P., \& Wiliam, D. (1998) Inside the Black Box - Raising Standards Through Classroom Assessment. London: Department of Education and Professional Studies, Kings College

Black, P., \& Wiliam, D. (2003) In Praise of Education Research: Formative Assessment. British Education Research Journal

Dewanyani, S. (2017). Menghidupkan Literacy di Ruang Kelas. Yogjakarta: PT. Kansus

Hanemann, H., \& McKay, U. V. (2015). Lifelong Literacy: Towards a New Agenda, Journal Springer Science+Business Media Dordrecht and UNESCO Institute for Lifelong Learning 2015. Int Rev Educ, 61, 265-272, DOI 10.1007/s11159015-9497-6

Iosifescu, C. S. (2014) The Foundation of Success in Adult Learning. ProcediaSosial and Behavioral Sciences 142 403-409, DOI: 10.1016/j.sbspro.2014.07.700

Kementerian Pendidikan dan Kebudayaan (2014) Direktorat Jenderal Pendidikan Anak Usia Dini dan Pendidikan Masyarakat, Direktorat Pembinaan Pendidikan Keaksaraan dan Kesetaraan. Peta sebaran Penduduk Tuna Aksara Usia 15-59 tahun per provinsi dan kabupaten/kota se-Indonesia

Kementerian Pendidikan dan Kebudayaan (2015) Direktorat Jenderal Pendidikan Anak Usia Dini dan Pendidikan Masyarakat, Direktorat Pembinaan Pendidikan Keaksaraan dan Kesetaraan. Petunjuk Teknis Program Pendidikan Keaksaraan Dasar

Kementerian Pendidikan dan Kebudayaan. (2016). Direktorat Jenderal Pendidikan Anak Usia Dini dan Pendidikan Masyarakat, Panduan Penyelengaraan dan Pembelajaran Pendidikan Keaksaraan Dasar. Jakarta: Kemdikbud

Paulo, F. (1993). Pedagogy of the City ( translated by D. Macedo)

Peraturan Menteri Pendidikan dan Kebudayaan, No.86 Tahun 2014 tentang Pedoman Penyelenggaraan Pendidikan Keaksaraan Dasar

Sloane, P.F.E., \& Dilger, B. 2005: The competence clash-Dilemmata bei der Übertragung des 'Konzepts der nationalen Bildungsstandards' auf die berufliche Bildung.bwp@Berufs- und Wirtschaftspädagogik online, 8, 1-32 